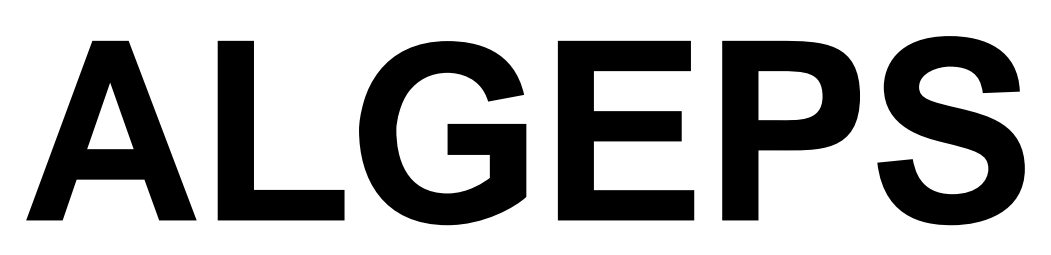

REVISTA DE GEOLOGIA, SÈRIE B no 590 - Maig del 2012

\title{
RECORRIDO DESDE BROTO A FANLO, A ESCALONA Y A LASPUÑA, A TRAVÉS DEL PATRIMONIO GEOLÓGICO Y MINERO DE LA COMARCA DEL SOBRARBE
}

Josep M. Mata-Perelló

Aquest recorregut va ésser experimentat amb docents el dia 14 DE JUNY DEL 2010 


\section{RECORRIDO DESDE BROTO A FANLO, A ESCALONA Y A LASPUÑA, A TRAVÉS DEL PATRIMONIO GEOLÓGICO Y MINERO DE LA COMARCA DEL SOBRARBE}

\section{ADVERTENCIAS PREVIAS}

Como en otros recorridos de RECONOCIMIENTO GEOLÓGICO (o de RECONOCIMIENTO GEOLÓGICO Y MINERO), el recorrido se compondrá de diversas PARADAS.

Por otra parte, habrá que tener en cuenta, en todo momento, (especialmente antes de empezar los recorridos de los diferentes tramos), el estado de los caminos y carreteras, por donde transitará el recorrido. Como es el caso del camino de acceso a las inmediaciones de Peña Montañesa, entre otros lugares...

Finalmente, como ya hacemos en otros recorridos similares, queremos decir que hace falta tener un cuidado muy especial en el respeto a la naturaleza, a lo largo de todo el recorrido del itinerario, y también fuera de él.

\section{BREVE INTRODUCCIÓN GEOLÓGICA}

Todo el recorrido de este itinerario, se desarrollará por distintas zonas ocupadas por el Sistema Pirenaico (o simplemente por los Pirineos). Concretamente, en todo el recorrido se circulará por el denominado Surpirineo Central.

Así, el recorrido se iniciará en las cercanías de Broto, dentro del denominado Surpirineo Central, por los denominados Pirineos Meridionales (también a menudo conocidos como Prepirineo Meridional).

Así, se irá circulando desde Broto hasta Fanlo y Laspuña, pasando del valle del Ara al Valle del Cinca.

\section{BREVE INTRODUCCIÓN GEOGRÁFICA}

El recorrido del presente itinerario se efectuará exclusivamente por una comarca aragonesa, por la del Sobrarbe. Así el recorrido se iniciará en la población de Broto, para ir hacía Fanlo, Escalona y Laspuña, en cuyo término municipal finalizará, cerca de la conocida Peña Montañesa... 
Por otro lado, la totalidad del recorrido transitará por la cuenca del río Ara, por el Valle de Viu. Luego ser continuará por los afluentes del río Bellos, descendiendo hasta el valle del río Cinca.

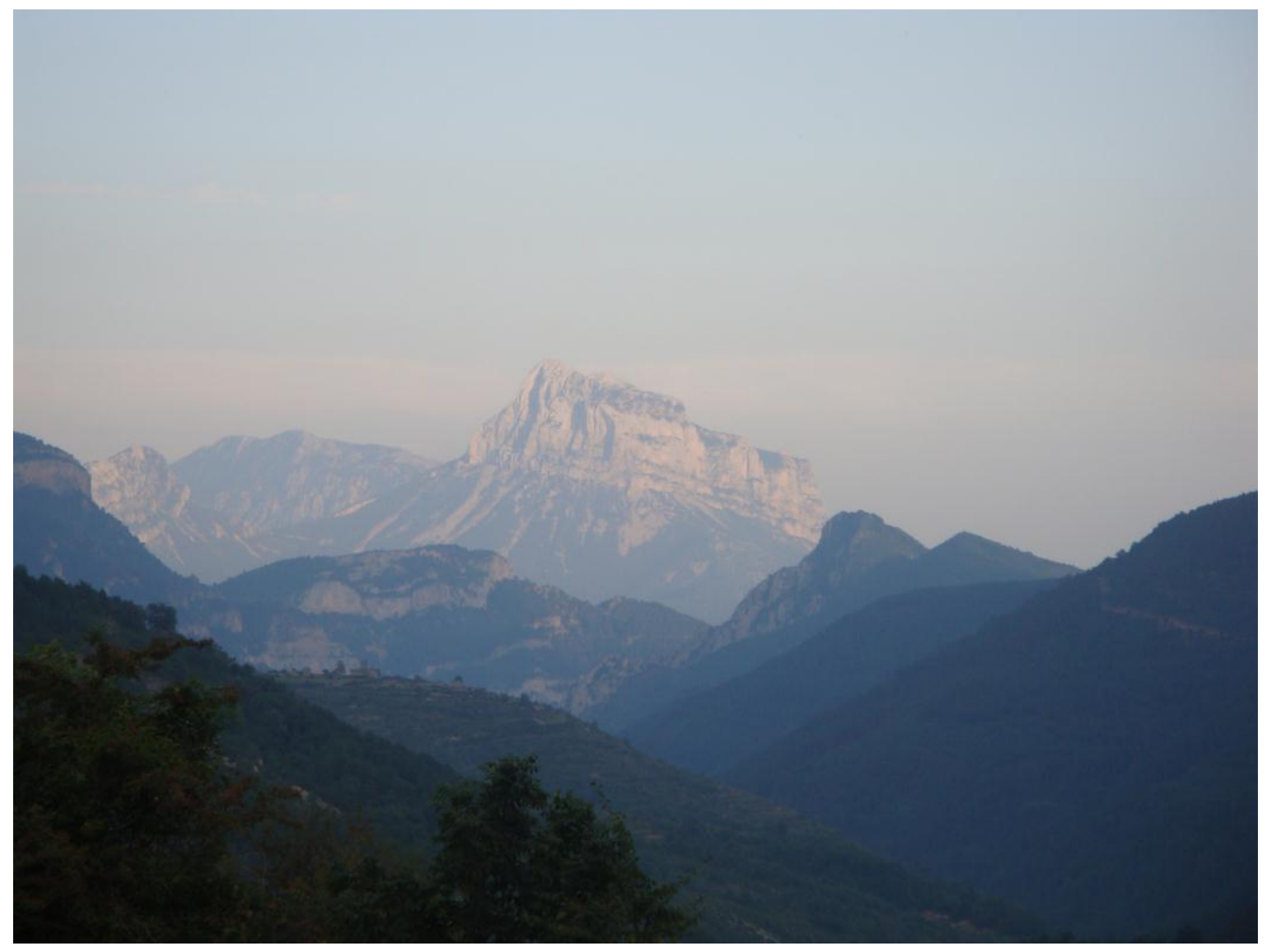

Peña Montañesa

\section{OBJETIVOS GENERALES DE ESTE ITINERARIO}

En este itinerario, los objetivos generales que se han de conseguir, se pueden concretar en los siguientes aspectos:

1.- Estudio y reconocimiento de los materiales mesozoicos y cenozoicos situados en el Surpirineo Central. Estos materiales los iremos encontrando a lo largo de todo el recorrido del itinerario.

2.- Estudio y reconocimiento de las estructuras del Surpirineo Central, a lo largo de todo el recorrido del itinerario.

3.- Visión de algunas de las antiguas explotaciones mineras encontradas a lo largo del recorrido del itinerario.

4.- Visión de los diferentes lugares directamente relacionados con el Patrimonio Geológico que iremos encontrando a lo largo del recorrido de este itinerario. Dentro de este, cabe considerar todo el relacionado con el imponente Valle de Añisclo; asícomo con la Peña Montañesa, entre otros lugares. 
5.- Visión de los diferentes lugares directamente relacionados con el Patrimonio Minero que veremos a lo largo del recorrido de este itinerario.

\section{ANTECEDENTES BIBLIOGRÁFICOS}

En relación con este itinerario, no conocemos ningún antecedente, de otro autor relativo a otro itinerario que discurra por este lugar. Tampoco nosotros hemos escrito ningún itinerario que discurra por estos lugares. Así pues, en este sentido el que ahora presentamos va a ser una primicia en todos los aspectos.

Por otra parte, haremos mención de algunos trabajos, de carácter geológico generalista, que corresponden a los trabajos del IGME (1972, 1974 y 1975), relativos al Mapa Geológico de España (a Escala 1.200.000), al Mapa Metalogenético de España y al Mapa de Rocas Industriales de España.

Con respecto a las mineralizaciones que iremos encontrando, mencionaremos los trabajos de: CALVO et altri (1988); MAESTRE (1845); así como nuestros trabajos: MATA-PERELLÓ (1987 y 1992).

También mencionaremos el trabajo de PRAMES (2005) dedicado a la comarca del Sobrarbe. Así como el del GOBIERNO DE ARAGÓN (2001), dedicado a los Puntos de Interés Geológico de Aragón.

Finalmente, diremos que todos estos trabajos (así como otros que ahora no hemos aludido), figurarán mencionados, por orden alfabético, en el apartado dedicado a las REFERENCIAS BIBLIOGRÁFICAS.

\section{RECORRIDO DEL ITINERARIO}

Este recorrido se iniciará en las inmediaciones de la población de Broto, desde donde se dirigirá hacía Sarvisé. En ese lugar se tomará por la derecha una carretera que se encamina ascendiendo hacía Fanlo. En este recorrido se efectuaran dos paradas: una en una curva sobre el Valle de Chale, y la otra en Fanlo.

Luego, el recorrido empezará a descender por el valle del río Aso, pasando por las inmediaciones de Buisan y de Nerín. Así, descendiendo, se llegará al cruce con la carretera de Vió. Se tomará momentáneamente, haciendo una hijuela, para efectuar una nueva parada.

Tras ello, el recorrido retornará hacía el cruce, para continuar bajando por el valle del río Aso, hasta llegar al Molino de Aso. En sus inmediaciones, cerca de la confluencia con el río Bellos, se hará una nueva parada.

Tras ello, el recorrido descenderá por el río Bellos, efectuándose una nueva parada aguas abajo, cerca del puente sobre el río. Después el recorrido se encaminará hacía Escalona, para seguir posteriormente hacía Laspuña y Ceresa, efectuándose la 
última parada de este recorrido en las inmediaciones de Peña Momtañesa, muy cerca de la última población citada.

\section{DESCRIPCIÓN DEL ITINERARIO}

Como de costumbre, haremos una serio de PARADAS (o ESTACIONES), en donde se realizaran diversas explicaciones en torno a las características del lugar en donde se halla la PARADA.

Por otra parte, en ellas haremos mención del término municipal dónde se encuentran, así como del número del "Mapa Topográfico Nacional (a escala 1:50.000, que indicaremos entre paréntesis. Así, ahora (en este recorrido) utilizaremos solamente las hojas: 178 (o de Broto), 179 (o de Bielsa) y 212 (o de Campo).

Así, la relación ordenada de las paradas que constituyen el recorrido de este itinerario, es la siguiente:

PARADA 1. CURVA DE LA CARRETERA SOBRE EL RÍO CHALE, (Sarvisé, término municipal de Broto, comarca del Sobrarbe). (Hoja 178).

El recorrido del presente itinerario, cabe iniciarlo en las cercanías de Broto. Ahí nos convendrá bajar hasta Sarvisé, por la carretera N-260. Al llegar a ese pueblo, convendrá tomar la carretera que conduce a Fanlo. A unos 2’5 Km de Sarrvisé (y a unos 6 de Broto) haremos la primera parada.

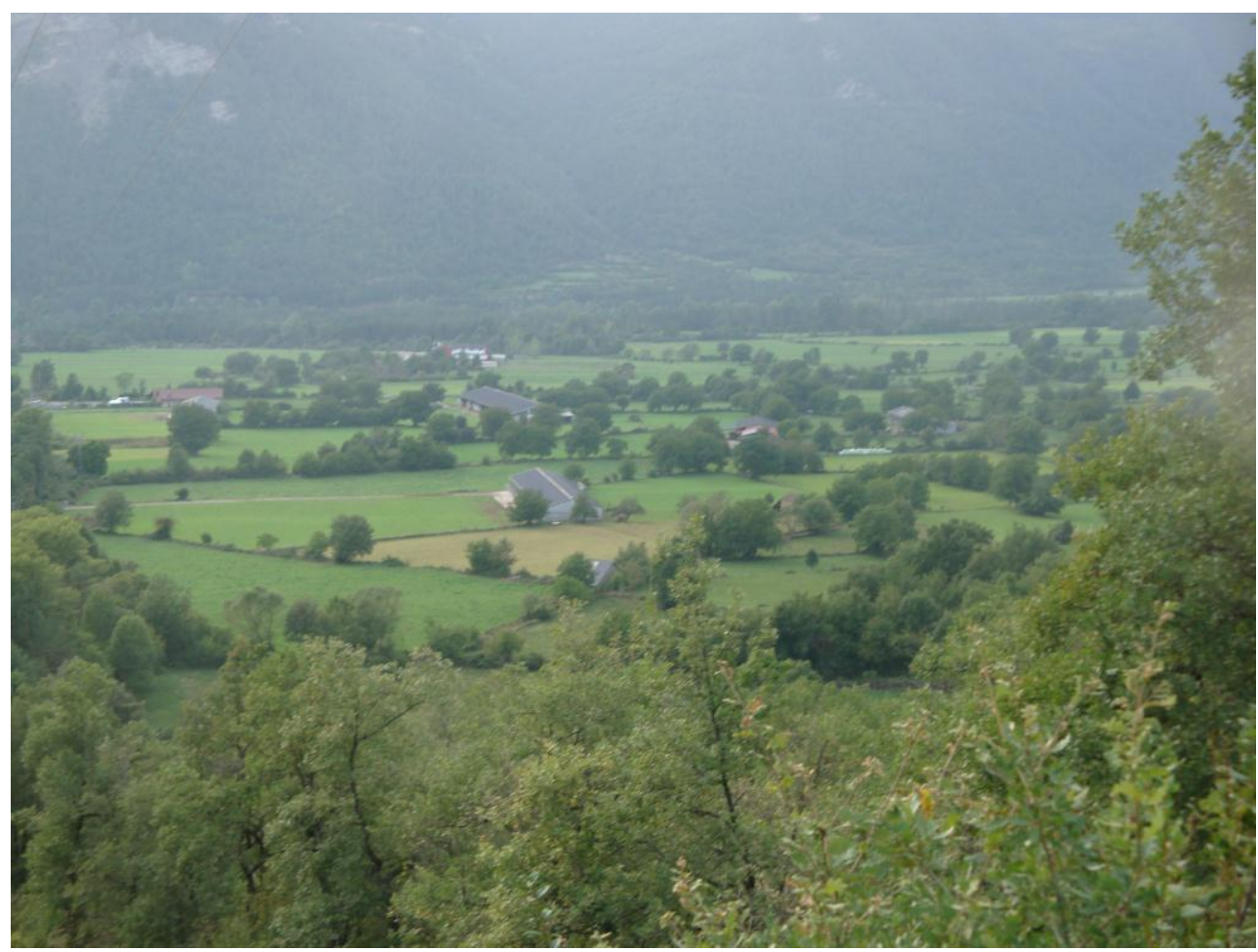

La planicie de Planduvial 
En este recorrido habremos ido encontrando afloramientos de los materiales mesozoicos y cenozoicos que forman parte de los Pirineos Meridionales, en donde nos encontramos ahora situados.

Por otra parte, desde Broto, hemos bajado junto al río Ara, recorriendo una planicie (la de Planduvial). Esta planicie se relaciona con una antigua laguna de origen glaciar, colmatada por los sedimentos del río Ara y de sus afluentes. Precisamente ahora, desde este lugar, estamos viendo esta planicie. Ésta se extiende desde las inmediaciones de Asin de Broto y Broto.

\section{PARADA 2 - CONDICIONAL. CONGOSTO DEL BARRANCO DEL VALLE, (término municipal de Fanlo, comarca del Sobrarbe). (Hoja 178).}

Después de realizar la parada anterior, cabe continuar por la carretera que asciende hacía Fanlo. Al llegar al pueblo, podemos efectuar una nueva parada, a unos 8 Km de la anteriormente realizada.

En este recorrido, hemos ido encontrando afloramientos de los materiales citados en la parada anterior, los cuales pertenecen a los Pirineos Meridionales, en donde continuamos situados.

Desde este lugar, mirando al Norte de Fanlo, es posible ver un congosto abierto por el río del Valle. Éste ha sido abierto entre afloramientos carbonatados del Cretácico.

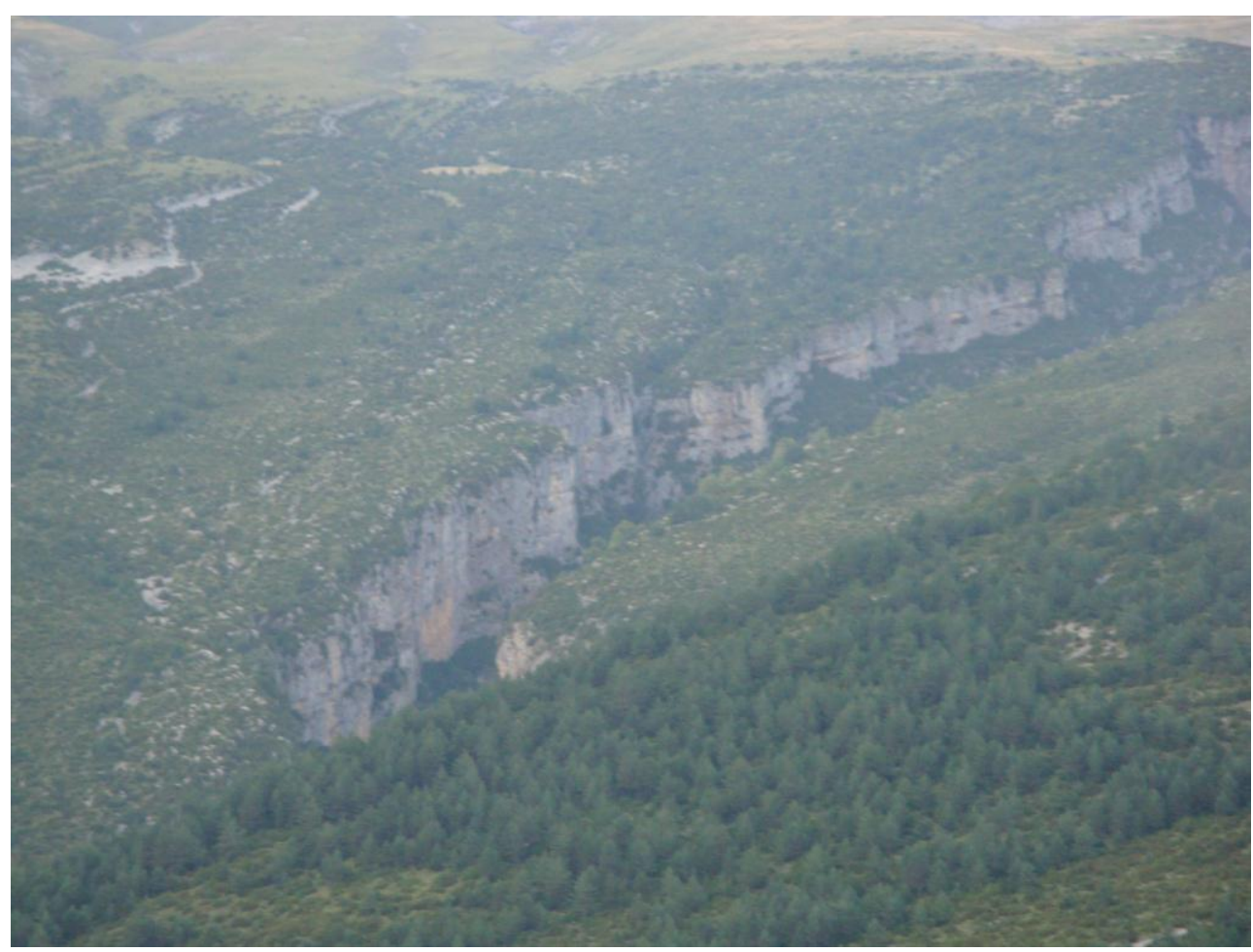

El Barranco del Valle 
PARADA 3. MIRADOR DE LA CARRETERA A VIO Y A BUERBA, (término municipal de Fanlo, comarca del Sobrarbe). (Hoja 178).

Desde la parada anterior, es necesario continuar por la carretera que conduce hacía el levante, descendiendo siempre por el valle del río Aso. En este descenso pasaremos cerca de los pueblos de Buisan y de Nerin, uno a la izquierda y otros a la derecha de la carretera. Luego llegaremos a un cruce. De el parte la carretera que se dirige a Vio y a Buerba. Esta carretera la tomaremos para hacer una hijuela. Ésta la realizaremos a $3 \mathrm{Km}$ del cruce. Así, desde la parada anterior, habremos recorrido unos $8 \mathrm{Km}$.

En este recorrido habremos ido encontrando los materiales ya citados en la parada anterior, situados dentro de los Pirineos Meridionales. Estos son los materiales que afloran en el lugar en donde estamos.

Desde este lugar, mirando hacía el Norte, puede verse como el cañón de Añisclo (del río Bellos) se sitúa entre les materiales mesozoicos del Cretácico del Anticlinal de Mandoto.

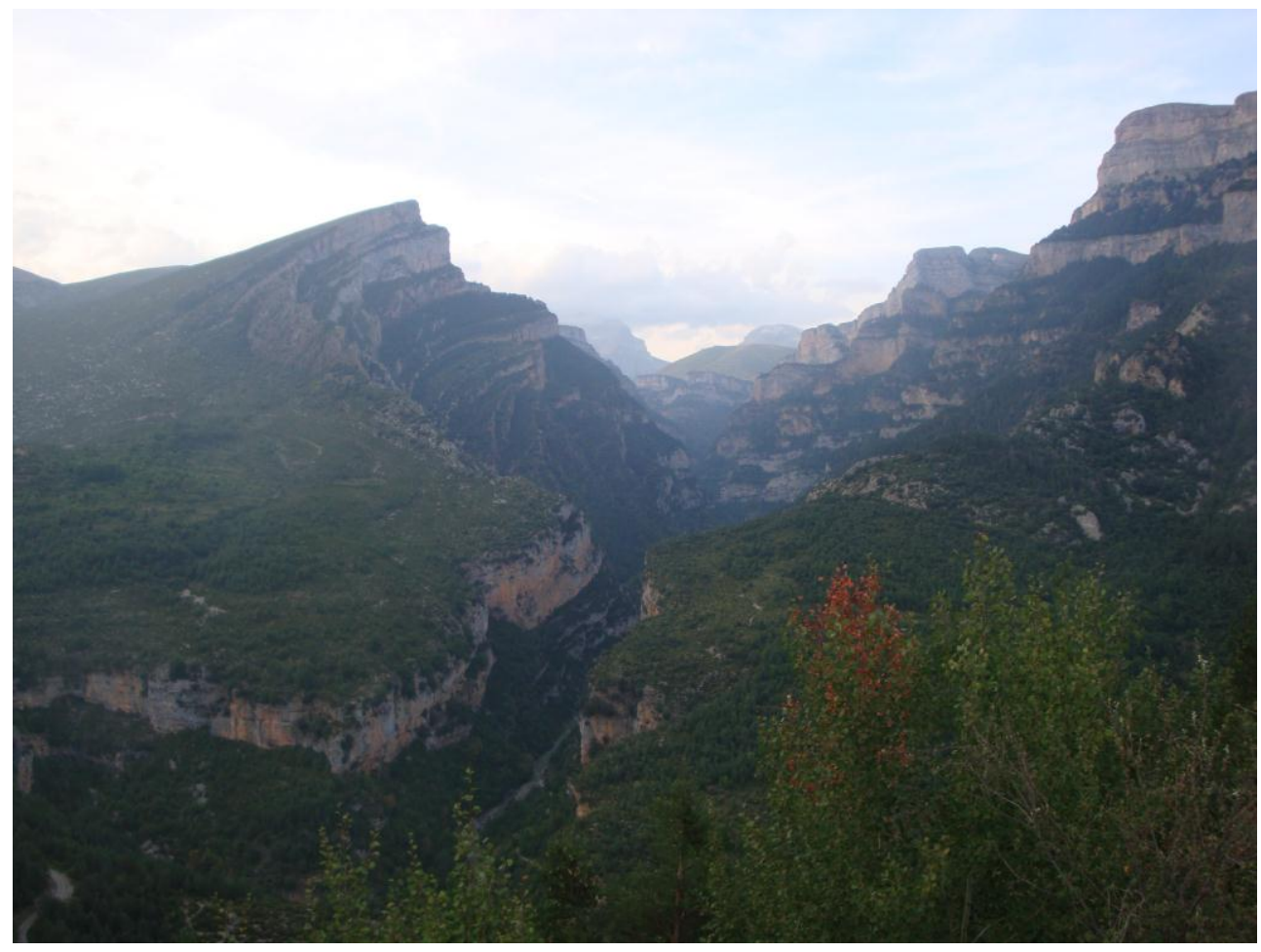

El Cañón de Añisclo y el Anticlinal de Mondoto

PARADA 4. INMEDIACIONES DEL PUENTE DEL MOLINO DE ASO, (término municipal de Fanlo, comarca del Sobrarbe). (Hoja 178).

Tras realizar la parada anterior, conviene retornar al cruce de carreteras, para bajar por la que conduce directamente a Escalona. Por esta carretera llegaremos pronto al Puente del Molino de Aso. Convendrá tomarlo, para efectuar una nueva parada. 
En este recorrido hemos ido encontrando los materiales citados en las paradas anteriores. Estos son los que aparecen en este lugar de la parada. Así, vemos por diferentes lugares los materiales carbonatados cretácicos.

Desde este lugar, nos encontramos sobre el río Bellos, cerca de su confluencia con el río Asa. Este río (el Bellos) forma un impresionante cañón.

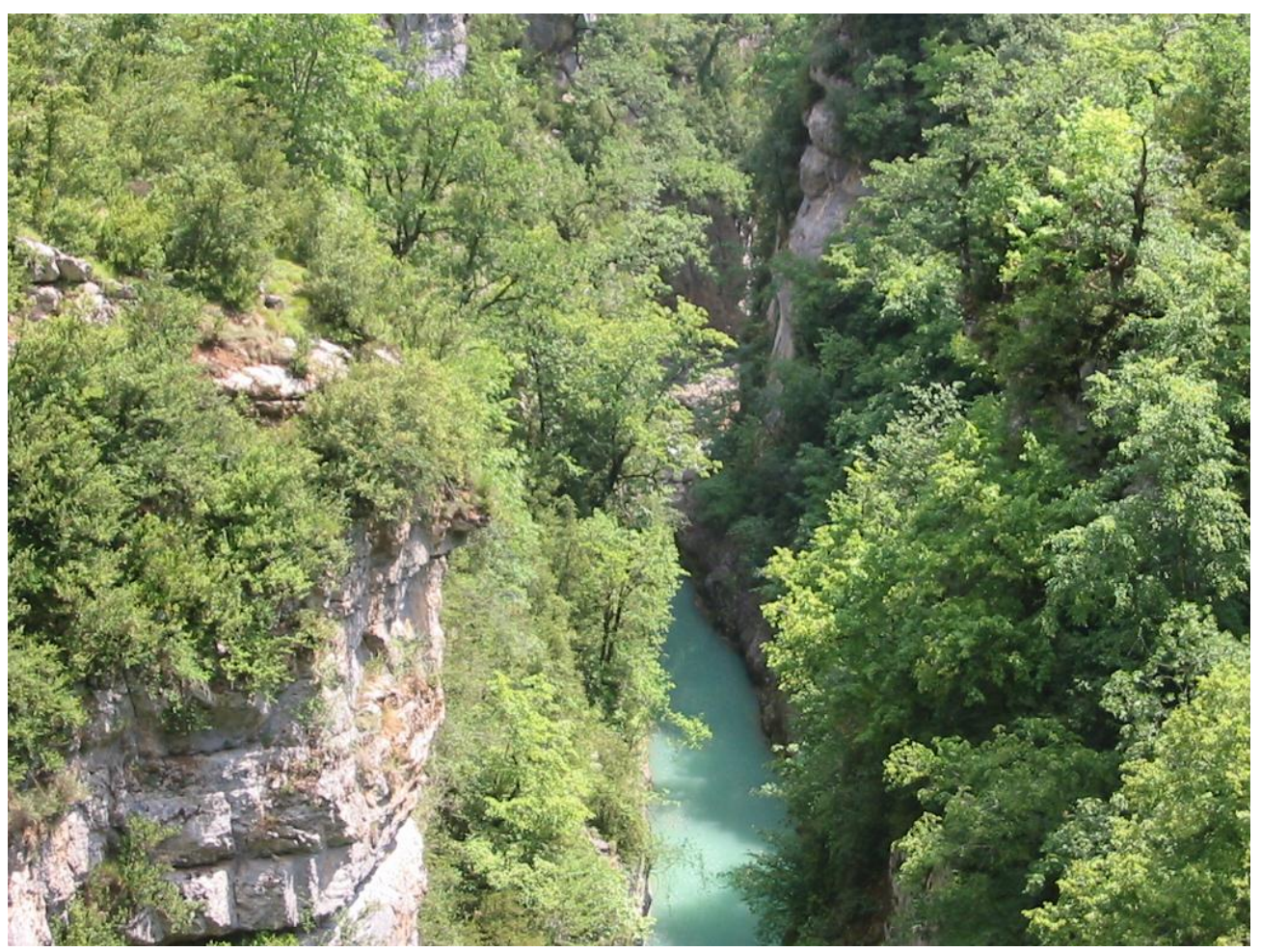

El Bellos, cerca del Puente del Molino de Aso

PARADA 5. PUENTE SOBRE EL RIO BELLOS, (término municipal de Puertolas, comarca del Sobrarbe). (Hoja 178).

Tras efectuar la parada anterior, cabe continuar bajando por el río Bellos, en dirección hacía Escalona. En este recorrido, por impresionantes lugares, al llegar al puente sobre el río Bellos, efectuaremos una nueva parada, a unos $10 \mathrm{Km}$ de la anteriormente realizada.

En este recorrido, nos habremos ido desplazando de Este a Oeste, siguiendo siempre el río Bellos (afluente del Cinca). Este recorrido es sumamente peligroso, ya que cabe considerar que es una carretera muy estrecha, sin la posibilidad de ir efectuando paradas. Por otra parte, esta carretera presenta intermitencias alternativas.

En este recorrido iremos pasando por lugares sumamente interesantes de de todos los puntos de vista geológicos. Así, encontraremos un deslizamiento (a la izquierda del río y de la carretera). Luego, habremos visto unas interesantes formas de morfología kársticas, al mismo lado de la carretera. Más abajo encontraremos los indicativos de una estación termal. 

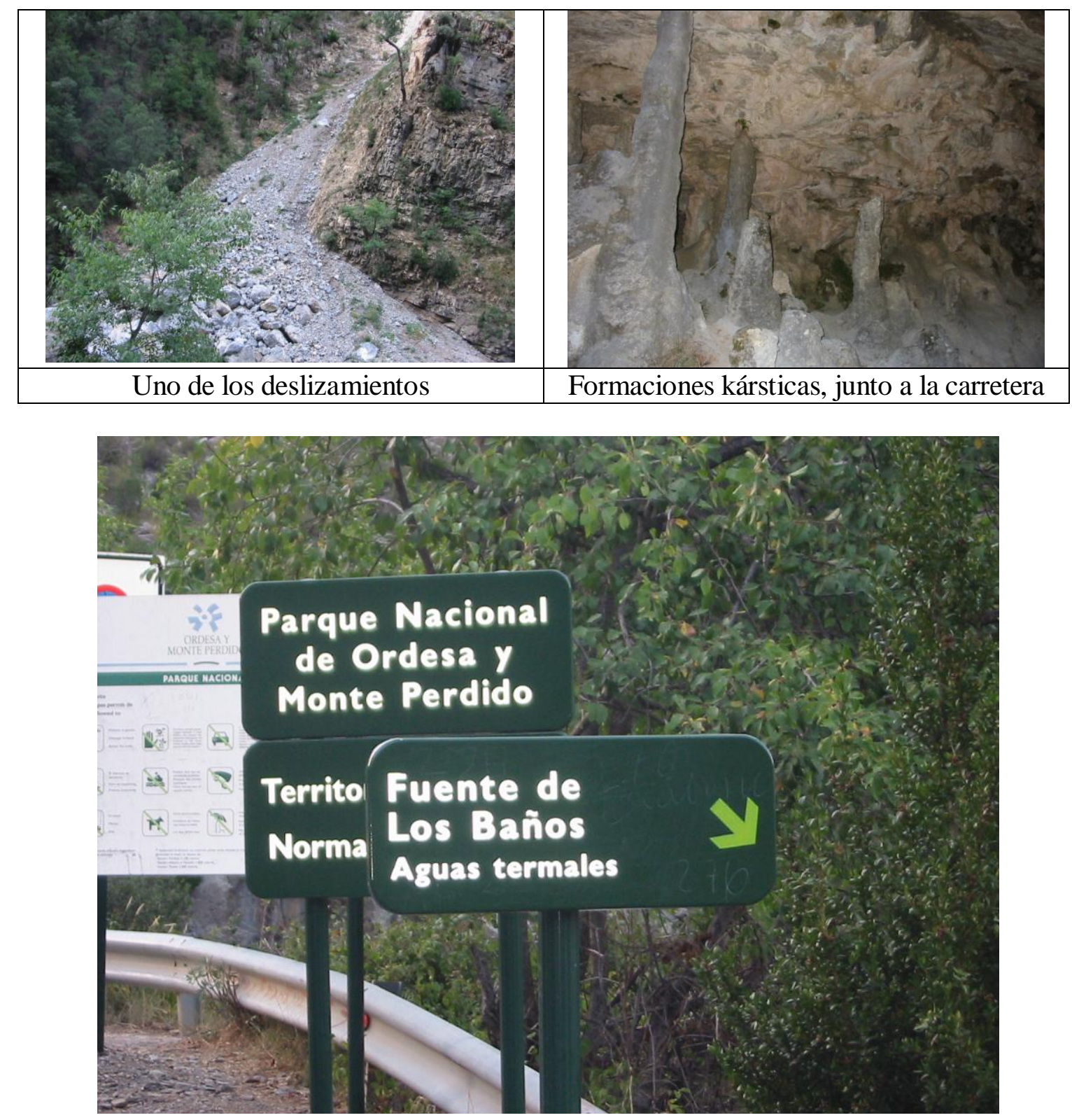

Plafones indicativos de los baños termales

PARADA 6. PEÑA SOLANA Y PEÑA MONTAÑESA, (Ceresa, término municipal de Laspuña, comarca del Sobrarbe). (Hoja 179).

Después de efectuar la parada anterior, convendrá continuar hacía el Este por la carretera que transcurre junto al río Bellos. Así, pronto pasaremos por Puyarruego y luego llegaremos a Escalona. Ahí encontraremos la carretera que enlaza l'Ainsa con Bielsa. La tomaremos brevemente hacía el Norte, hasta encontrar el desvío a la derecha, de la carretera de Laspuña. La tomaremos. Al llegar a ese pueblo, seguiremos hacía Ceresa. Finalmente, desde ahí nos acercaremos a Peña Solana y a Peña Montañesa. En la base de la primera efectuaremos una nueva parada, la última de este recorrido, a unos $10 \mathrm{Km}$ de la anteriormente efectuada. 
En este recorrido hemos ido encontrando los materiales mesozoicos citados anteriormente en las paradas anteriores. Así, es de destacar los importantes afloramientos de calcolutitas situados entre Escalona y Laspuña.

Luego, en el lugar de la parada, podemos observar los relieves de la Peña Solana y de la Peña Montañesa. El primer relieve forma parte del Manto del Cotiella; mientras que el segundo de la Escama de la Sierra de Ferreras.

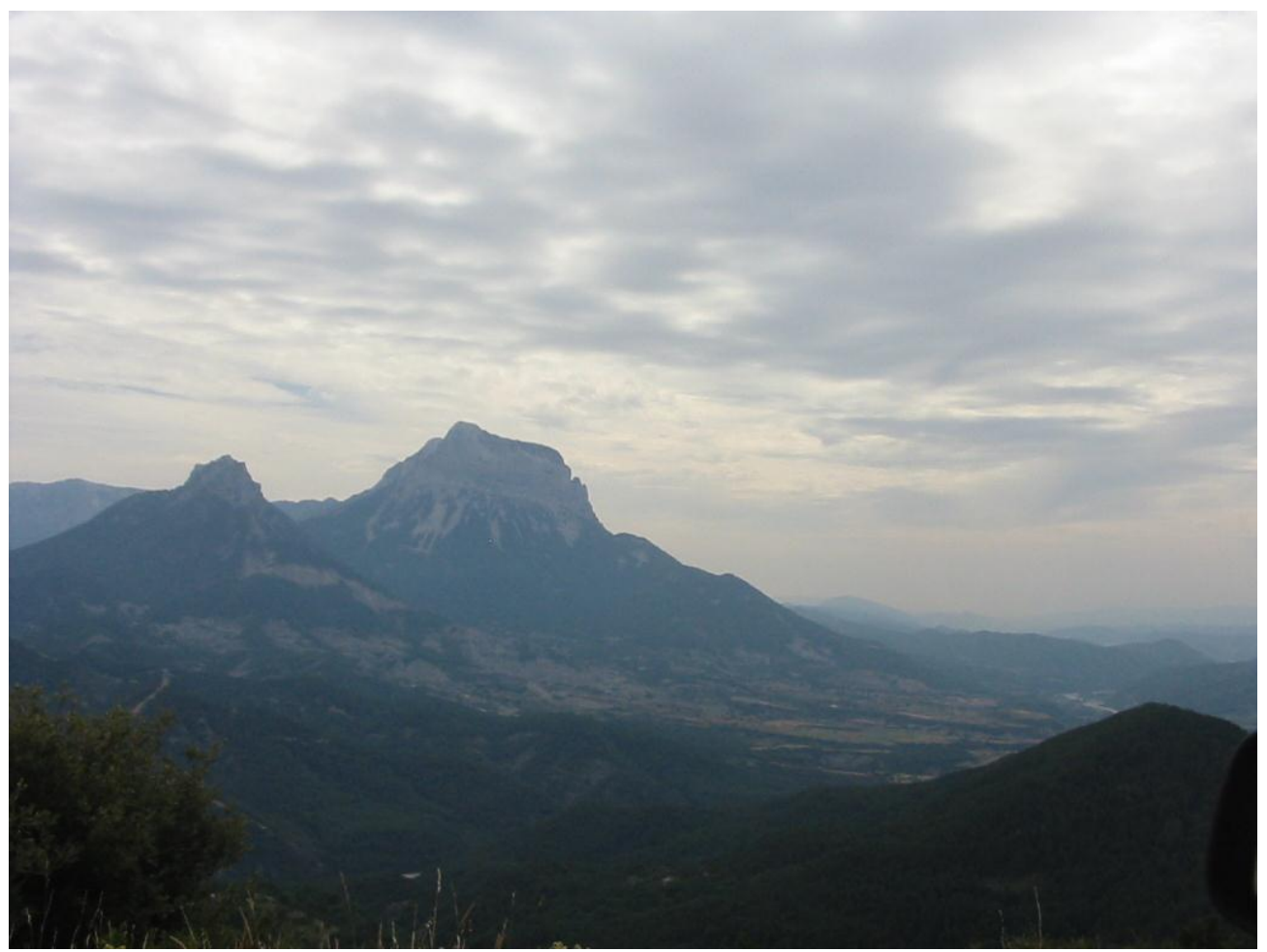

Peña Solana y Peña Montañesa

\section{EN ESTE LUGAR FINALIZA EL ITINERARIO}

\section{BIBLIOGRAFÍA}

CALVO, M. et altri (1988). - Minerales de Aragón, Colección Temas Geológicos, 207 Pág. Zaragoza

GOBIERNO DE ARAGÓN (2001).- Puntos de Interés Geológico de Aragón. Consejería de Medio Ambiente del Gobierno de Aragón. Zaragoza

IGME (1972).- Mapa Geológico de España a escala 1:200.000 (Síntesis de la cartografía existente). Hoja y Memoria na 23 (Huesca). Inst. Geol. Min. España 


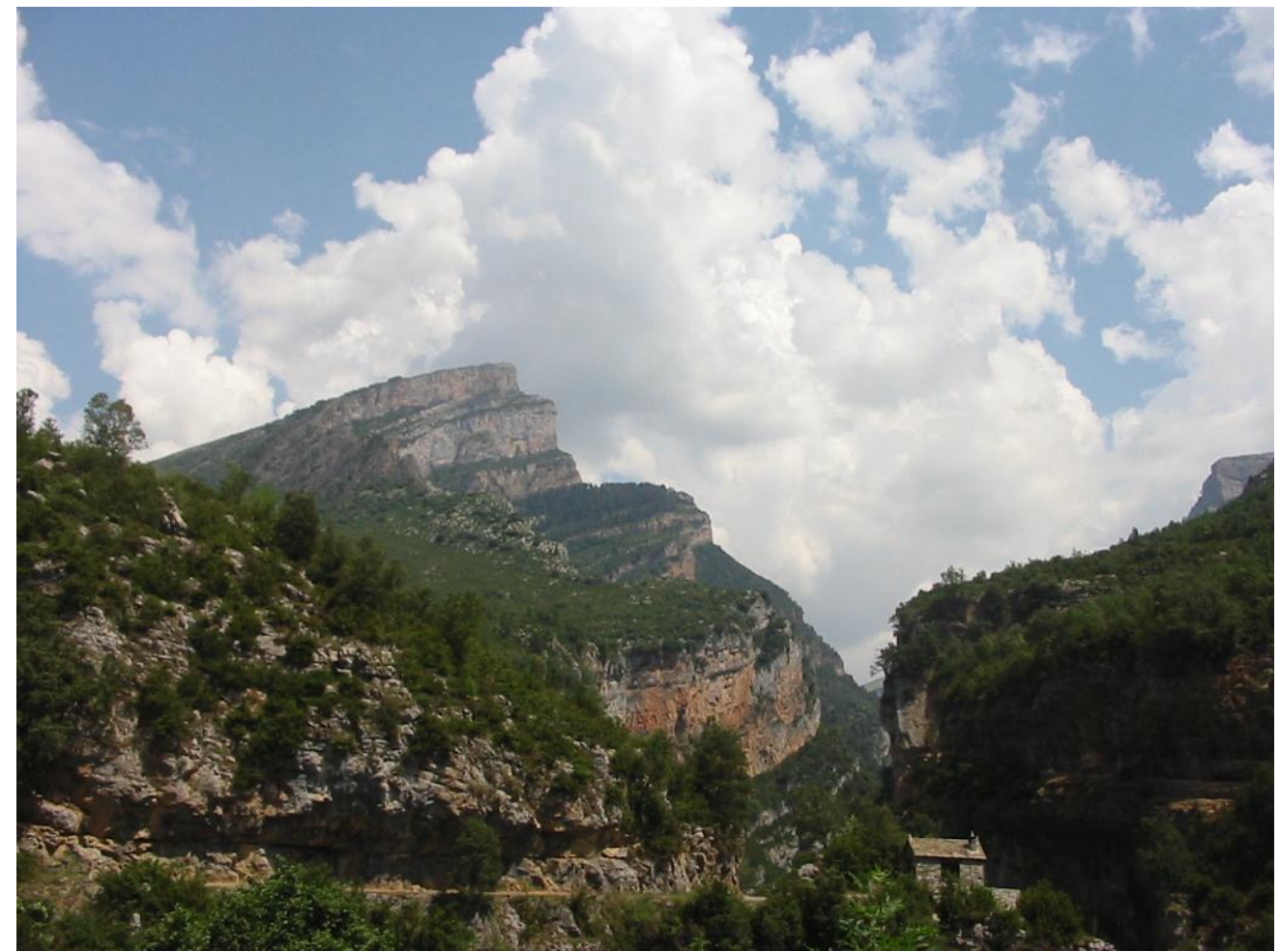

ANTICLINAL DE MONDOTO, DEL VALLE DE AÑISCLO

IGME (1973).- Mapa Metalogenético de España a escala 1:200.000. Hoja y Memoria ${ }^{a}$. 23 (Huesca). Inst. Geol. Min. España

IGME (1975).- Mapa de Rocas Industriales de España a escala 1:200.000. Hoja y Memoria $n^{a} .23$ (Huesca). Inst. Geol. Min. España

MAESTRE, A. (1845).- Descripción geognóstica del Distrito Minero de Cataluña y Aragón. Anales de Minas, t. III. Madrid

MATA - PERELLÓ, J.; (1987).- Introducción al conocimiento de las mineralizaciones aragonesas. Mineralogistes de Catalunya, t.III, pp. 258-265. Barcelona

MATA - PERELLÓ, J.M. (1992).- Inventario Mineralógico de la comarca del Sobrarbe. Rodeno, 13. 42 Pág. Manresa

MATA - PERELLÓ, J.M. y SANZ-BALAGUË, J. (1992).- Guía de Identificación de Minerales, adaptada fundamentalmente a la Península Ibérica. Edic. Parcir, 243 pag. Manresa 
PRAMES (2005).- Sobrarbe. Colección RUTASCAL por Aragón. Prames, Gobierno de Aragón. 119 pag. Zaragoza. 